\title{
Pluriatividade Rural: a percepção de agricultores de Lages, Santa Catarina, sobre a oferta de hospedagem
}

\section{Rural Pluriactivity: the perception of farmers of Lages, Santa Catarina (Brazil), on the offer of lodging}

\author{
Gustavo Costa Ribeiro ${ }^{1}$ \\ Tiago Savi Mondo ${ }^{2}$
}

\begin{abstract}
RESUMO - Apesar da forte tradição agrícola do Brasil há, no âmbito nacional, um grande fluxo migratório para as cidades, em detrimento da atividade rural principal, notadamente a agricultura familiar. $O$ objetivo deste artigo foi verificar a disponibilidade de ofertar lazer e hospedagem, de pequenos proprietários que estavam exercendo agricultura familiar na zona rural de Lages, Santa Catarina (SC), e qual o impacto de uma possível renda extra no desejo de ali permanecer. Tentou-se identificar, com o auxílio de entrevistas semiestruturadas, as possibilidades e oportunidades de manutenção de pequenos produtores rurais em suas atividades principais, apesar da sazonalidade característica das ocupações rurais, com a incorporação de atividades relacionadas à hospedagem. Foi utilizada a pesquisa de campo como método de pesquisa. Como resultado, mostrou-se ser relevante a possibilidade de auferir renda extra com inclusão de hospedagem em suas propriedades, apesar do desconhecimento das atividades relacionadas ao turismo, ou ainda das limitações estruturais e necessidade de investimentos para uma melhor adequação das instalações. Outro fator apurado refere-se ao relacionamento entre vizinhos, que necessitaria ser mais bem compreendido e mediado.
\end{abstract}

Palavras-chave: Turismo. Atividade rural. Hospedagem. Renda. Manutenção no campo.

ABSTRACT - In spite of the strong Brazilian agricultural tradition, there is, at a national level, a great migratory flow to the cities, in detriment of the main rural activity, notably the family farming. The aim of this article was to verify the availability of offering leisure and accommodation in small properties where there are family farms in the rural areas of Lages, Santa Catarina (SC), Brazil and the impact of a possible

\footnotetext{
${ }^{1}$ Tecnólogo em Hotelaria pelo Instituto Federal de Santa Catarina (IFSC). Graduado em Pedagogia pela Universidade do Estado de Santa Catarina (UDESC). Pós-graduado em Gestão de Pessoas nas Organizações pela Universidade Federal de Santa Catarina (UFSC). Técnico em laboratório na UFSC. E-mail: gc.ribeiro@gmail.com

2 Estágio de Pós-doutorado na Universidade Federal do Paraná (UFPR). Doutor em Administração pela Universidade Federal de Santa Catarina (UFSC). Professor do Instituto Federal de Santa Catarina. E-mail: tiago.mondo@ifsc.edu.br
} 
extra income on their desire to stay in those places. It was sought to identify, with the help of semi-structured interviews, the possibilities and opportunities of maintaining the small rural producers in their main activities, despite the seasonal characteristic of rural occupations, with the incorporation of activities related to lodging. It was used field research as method. Then, it was found to be relevant the possibility of obtaining extra income with the inclusion of accommodation service in their properties, despite the lack of knowledge of the activities related to tourism, or yet the structural limitations and the need for investments in order to improve the adequacy of the facilities. Another factor verified was the relationship between neighbors, which needs to be better understood and mediated.

Keywords: Tourism. Rural activity. Lodging. Income. Maintenance in the field. 


\section{INTRODUÇÃO}

A região do município de Lages, Santa Catarina (SC), foi uma das pioneiras na implantação das atividades de turismo rural no Brasil, integrando as atividades turísticas e de hospedagem às atividades rotineiras de propriedades produtivas. A geografia local, com paisagens marcadas pelo relevo montanhoso do altiplano catarinense é propícia para os apreciadores de atividades ao ar livre, possíveis quando em espaço privilegiado e preparado para tal. A região serrana de Santa Catarina, além do seu patrimônio natural, conta ainda com patrimônio cultural de relevância na história da colonização dos estados do sul do Brasil.

Já mais pontualmente, a região que foi tema do presente estudo conta com uma represa para abastecimento de água para operação da Usina Hidrelétrica do Salto do Rio Caveiras, ali construída. Este fato, por si só, possibilitou um sem fim de possibilidades turísticas, uma vez que criou um grande lago artificial, com uma vasta região alagada. Percebeu-se, contudo, a falta de oferta de meios de hospedagem que permitissem uma utilização mais democrática destes espaços e suas proximidades.

Desde o início da industrialização ocorrida no Brasil, tem-se percebido um fenômeno frequente e intenso: o empobrecimento dos pequenos produtores rurais e sua consequente migração às periferias empobrecidas e não qualificadas dos centros urbanos. A região de estudo deste trabalho, localizada na zona rural de Lages (SC), incluída aí a família do pesquisador, não fugiu à regra, onde sua população também passou a enfrentar os rigores das entressafras ou safras insatisfatórias, o que tem provocado o inchaço das periferias da cidade de Lages e em outras no seu entorno.

Como causa de tal situação, percebeu-se, dentre outros motivos, a falta de rendimentos, de liquidez monetária continuada das atividades rurais. A liquidez está relacionada diretamente ao sucesso de colheita e venda da safra ou dos produtos agrícolas a ela condicionada.

Contudo, verificou-se um grande número destes produtores residindo em casas antigas, de arquitetura típica característica, em locais privilegiados e exercendo atividades que estão ganhando um novo significado, uma vez que o retorno às origens ao campo e sua consequente (re)valorização tem se mostrado uma tendência a nível mundial. Lindner et al. (2009) afirmaram que o antagonismo existente entre os espaços urbanos e rurais já não estavam sendo preponderantes, seja graças aos avanços nas 
comunicações, seja a modernização das atividades a que todos os ambientes estão sujeitos.

Uma das formas de revalorização das atividades do campo é a oferta de lazer e acomodação para turistas, o saber fazer ofertado como atrativo e as estruturas físicas ofertadas como meios de hospedagem sem que sejam descaracterizadas enquanto propriedades e edificações rurais. Observa-se que:

[...] no 'novo rural brasileiro', muitos habitantes da área rural, devido as dificuldades de reprodução sócio-econômica, passam a exercer concomitantemente com as atividades agrícolas, atividades não-agrícolas como forma de manter a permanência no campo, nesse caso as novas ruralidades representariam uma forma de valorização do rural. (LINDNER et al.; 2009, s.p.).

Desta forma, aliar atividades de hospedagem / acolhimento juntamente com o uso dos seus bens passivos, seu saber-fazer ou seu estilo de vida, poderia ser uma alternativa viável para os períodos de entressafra, onde os recebimentos oriundos da atividade agrícola são escassos. O sitiante reconhece algum valor em seu dia a dia, o qual alguém estaria disposto a pagar para vivenciá-lo? Seria possível conciliar atividades típicas de hotelaria com atividades típicas de produção rural?

Pretendeu-se verificar de que forma uma possível renda extra, oriunda da oferta de lazer e hospedagem em suas propriedades, impactaria na qualidade de vida e no desejo de permanência na zona rural, de três pequenos proprietários e produtores que exercessem atividades de agricultura familiar.

O motivo deste estudo foi identificar possibilidades e oportunidades de manutenção de três pequenos produtores rurais em suas atividades principais, apesar da sazonalidade característica das ocupações rurais, com a incorporação de atividades relacionadas à hospedagem, e consequente fonte de renda com liquidez mais imediata e fluxo relativamente constante. Considera-se que este estudo poderá contribuir para uma melhor percepção quanto à possibilidade de poder ofertar a hospedagem como aliada, no sentido de suprir as necessidades básicas dos moradores distantes de centros urbanos, cujos ciclos de abundância e renda estão diretamente ligados aos períodos de safras, mas que passam por momentos de grandes privações, principalmente em momentos de entressafras. 
Acredita-se que esta pesquisa seja relevante, uma vez que a necessidade de manutenção das atividades agrícolas é vital para qualquer sociedade, principalmente as ocidentais, que relegam as atividades ligadas ao campo como secundárias e de menor importância. Contudo, constata-se que o consumo de alimentos e de uma infinidade de itens em qualquer centro urbano depende majoritariamente de produtos oriundos do campo.

\section{REFERENCIAL TEÓRICO}

Procurou-se, na elaboração do referencial teórico que embasou o presente trabalho, conceituar os temas que permeiam e que permitam conduzir o leitor ao entendimento dos assuntos relevantes que culminam na abertura das propriedades rurais a estranhos a ela.

Partiu-se da explicação daquilo que se entende ser a atividade rural no Brasil, suas dificuldades e desafios enquanto atividade econômica para pequenos produtores.

Após, procurou-se explicar algum entendimento de pluriatividade rural, e de que forma este tema se conectava ao interesse das famílias em sua manutenção no campo. Feitas as considerações sobre a manutenção nas atividades agrícolas, foram abordados dois temas intimamente relacionados ao assunto: a pobreza relativa no campo, e o êxodo rural.

Por fim, procurou-se explorar o turismo e a atividade hoteleira rural, não sob a perspectiva de desqualificar ou minimizar a importância das atividades agrícolas, mas sim como uma alternativa viável de negócio, que vem a somar e a garantir uma qualidade de vida digna aos campesinos.

\subsection{A ATIVIDADE RURAL NO BRASIL}

As transformações recentes do mundo rural brasileiro são marcadas por dois fatos importantes. Um deles é o reconhecimento, pela primeira vez na história, da agricultura familiar como um ator social importante, sendo o Programa de Apoio à Agricultura Familiar (PRONAF) uma expressão dessa valorização. 
O outro fato está relacionado à demanda pela terra e aos assentamentos de reforma agrária. Isso se traduziu na revalorização do rural como lugar para se trabalhar e para se viver (WANDERLEY, 2000 apud NASCIMENTO, 2005). O meio rural seria então um espaço diferenciado, não sendo mais apenas um lugar de produção agropecuária, mas um meio capaz de proporcionar aos citadinos padrões de residência bastante específicos, além de ser espaço para formas de lazer ligadas ao contato com a natureza (WANDERLEY, 2002 apud NASCIMENTO, 2005).

Um dos mais importantes fenômenos demográficos, sociais e culturais do início do milênio é a revalorização das regiões interiores, pois:

\footnotetext{
[...] uma visão territorial do desenvolvimento pode revelar potenciais que, até hoje, o meio rural não revelou à sociedade. Visto como a base física da produção agrícola, seu destino dificilmente escapa à tragédia do esvaziamento social, econômico, político e cultural. Quando, entretanto, o meio rural é encarado, não como a simples sustentação geográfica de um setor (a agricultura), mas como base de um conjunto diversificado de atividades e de mercados potenciais, seus horizontes podem ser ampliados (ABRAMOVAY, 2000, p. 395).
}

De acordo com Veiga (2004 apud NASCIMENTO, 2005) tornou-se cada vez mais forte nos últimos 20 anos um fenômeno novo em todas as sociedades mais desenvolvidas, que diz respeito à atração que os espaços rurais exercem e que resulta do grande aumento da mobilidade com um crescente leque de deslocamentos. Segundo o autor, nos últimos tempos "as principais vantagens comparativas voltaram a ser riquezas naturais, mas de outro tipo. São os encantos do contexto rural - beleza paisagística, tranquilidade, silêncio, água limpa, ar puro - todas ligadas à qualidade do meio ambiente natural”. (VEIGA, 2004 apud NASCIMENTO, 2005).

\subsection{PLURIATIVIDADE RURAL}

Segundo Nascimento (2005), não há uma explicação única para a existência e reprodução da pluriatividade no Brasil. A literatura internacional e nacional acerca desse segmento social já demonstrou que ele não é um caso exclusivo de determinadas áreas rurais. Pelo contrário, a pluriatividade é uma realidade generalizada por todas as áreas rurais de todas as regiões e países pesquisados. 
Em virtude da heterogeneidade regional, ainda segundo o autor, o resultado das pesquisas registra também uma grande diversidade de fatores explicativos da existência da pluriatividade nas distintas regiões. $\mathrm{O}$ autor prossegue com o exemplo de regiões da Comunidade Econômica Europeia - CEE - com acesso a maiores centros urbanos e industriais e com um setor produtor de alimentos modernizado, onde é mais comum a pluriatividade como um meio de manter a atividade agrícola, sendo a renda não agrícola usada para apoiar a atividade agrícola; em regiões caracterizadas por apresentarem dificuldades na produção agrícola - seja em virtude de terem uma força de trabalho velha ou por serem bastante isoladas e terem dificuldade de diversificar suas atividades produtivas - a pluriatividade pode ser vista como um meio de diversificar os negócios.

Nesse sentido, a pluriatividade pode refletir uma variedade de estratégias familiares: a busca por inserção em novos mercados em resposta às dificuldades financeiras; uma tentativa de reduzir os riscos da atividade agrícola; ou ainda uma resposta às oportunidades surgidas nos mercados de trabalho e de produtos. Santos e Cunha (2007) afirma que a pluriatividade rural já vem de longa data, como capacidade de adaptação aos movimentos sociais emergentes.

Já (FULLER (1990, apud NASCIMENTO, 2005), assinala que a pluriatividade representa uma etapa de um processo de reconceitualização de agricultura a tempo parcial. A adoção do termo pluriatividade obedece a seu mais amplo significado ao estar referido a uma unidade econômica que realiza outras atividades além da agricultura, tanto dentro como fora da exploração, e pelas quais se obtém distintos tipos de remuneração. Para esse autor, entre as atividades realizadas pela unidade familiar agrária em adição à agricultura, incluem-se as seguintes: a) o emprego em outras explorações agrárias; b) as atividades derivadas da produção agrária no interior do estabelecimento, como a transformação de alimentos; c) as atividades não agrárias realizadas na exploração, como o turismo e o artesanato; e d) o emprego fora da exploração e do setor agrário.

Há diversos determinantes que levam as unidades familiares agrárias a empreenderem novas atividades, sendo eles internos ou externos à família. Dentre estes, pode-se citar as infraestruturas das economias locais, os recursos naturais, culturais e humanos como corresponsáveis pelo maior ou menor êxito da pluriatividade em um determinado território. Outro fator, ainda conforme Fuller (1990) apud Nascimento, 
(2005), está nas características dos membros da unidade familiar como as da exploração agrária, seja a idade dos seus membros, seja a capacitação dos mesmos.

As transformações ocorridas no ambiente econômico também têm sido preponderantes para a opção em empreender algo diferente da atividade principal, de modo que o novo ambiente que se configura oferece alternativas de ocupação e renda às famílias rurais, alternativas estas estranhas ao universo estritamente identificado com a agropecuária.

Para Sacco dos Anjos (2003) apud Nascimento (2005, p.44), devem-se:

\begin{abstract}
[...] incluir outros aspectos para chegar a um conceito integrado. A pluriatividade, portanto, não se trata de um fenômeno conjuntural, mas o resultado de um amplo processo de transformação da agricultura, em correspondente sincronia com a dinâmica da economia em geral e no marco da profunda reestruturação que atravessa o modelo de produção capitalista. Mas, por outra parte, sua consolidação nos distintos países adquire especificidades geográficas, econômicas, políticas e sociais [...] Em definitivo, parece igualmente lógico que não é possível interpretá-la sem levar em conta o contexto amplo que lhe engendrou.
\end{abstract}

Desta forma, pluriatividade caracteriza-se pela combinação das múltiplas inserções ocupacionais das pessoas que pertencem a uma mesma família. A emergência da pluriatividade ocorre em situações em que os membros que compõem as famílias domiciliadas nos espaços rurais combinam a atividade agrícola com outras formas de ocupação em atividades não-agrícolas. Ou seja, a pluriatividade resulta da interação entre as decisões individuais e familiares com o contexto social e econômico em que estas estão inseridas.

Nascimento (2005) afirma que, objetivamente, a pluriatividade refere-se a um fenômeno que pressupõe a combinação de duas ou mais atividades, sendo uma delas a agricultura. Esta interação entre atividades agrícolas e não-agrícolas tende a ser mais intensa à medida que mais complexas e diversificadas forem as relações entre os agricultores e o ambiente social e econômico em que estiverem situados. Isto faz com que a pluriatividade seja um fenômeno heterogêneo e diversificado que está ligado, de lado, às estratégias sociais e produtivas que vierem a ser adotadas pela família e por seus membros e, de outro, dependerá das características do contexto em que estiverem inseridas.

Conforme afirma Botelho Filho (2005), essa combinação permanente de atividades agrícolas e não-agrícolas, em uma mesma família, é que caracteriza e define 
o fenômeno da pluriatividade, que tanto pode ser um recurso do qual a família faz uso para garantir a reprodução social do grupo ou do coletivo que lhe corresponde como também pode representar uma estratégia individual, dos membros que constituem a unidade doméstica.

Tudo isto leva a pensar um novo significado ao mundo rural, o rural integrado às transformações do momento atual de (re)organização do espaço pelo capitalismo. O rural permanece como tal, mas recriado e integrado a novas lógicas. Moreira (2003) apud Botelho Filho (2005), pensando na questão da defesa dos patrimônios culturais e naturais, na multifuncionalidade de uso do território, afirma que este novo mundo rural passa agora por uma ressignificação, diversificação e redemocratização.

Lembra ainda, o autor, que essa ressignificação provocou uma valorização do "mundo rural", agora visto como algo a ser olhado como tendo valores a oferecer a quem os procura.

Por fim, a pluriatividade não ocorre de forma apenas marginal ou transitória, confinada a determinadas situações particulares, assim como também não representa um processo com tendência à generalização para todas as áreas rurais. $\mathrm{O}$ autor afirma que, embora não exclusivamente, a pluriatividade pode ser observada mais intensamente entre os agricultores familiares, especialmente naquelas regiões onde essa forma social possui uma história de ocupação do espaço e do território. É o caso da região de Lages (SC), objeto de estudo deste trabalho.

\subsection{POBREZA RELATIVA NO CAMPO}

A pobreza pode ser entendida como uma situação de carência de condições para satisfazer as necessidades básicas, capazes de permitir ao indivíduo ou a sua família recursos para supri-las.

Diversos pesquisadores são unânimes em reconhecer a disparidade da distribuição de renda, principalmente no Brasil. Segundo Schneider e Fialho (2000), a pobreza nas áreas rurais estava atingindo um maior número de pessoas e famílias que nas áreas urbanas, chegando à proporção de perto de 25\% para o urbano contra próximo aos $40 \%$ na área rural, indicando a participação significativa da pobreza rural sobre a proporção total de pobres. 
De forma mais intensa que em outras épocas, o estudo da pobreza rural passou também a se relacionar com outros problemas, como o desemprego crescente nos setores urbano-industriais, a pressão demográfica sobre as grandes cidades, a violência urbana etc., conforme afirma Schneider e Fialho (2000). Segundo os autores, atacar a pobreza no meio rural passou a ser uma medida social de retenção do problema no seu local de origem; ou seja, a estratégia continua a ser a de manter os pobres no campo (em décadas passadas falava-se em "fixar o homem no campo"), como se isto fosse possível em um país livre e democrático. Isso sem mencionar os outros problemas ligados à pobreza rural, como a reforma agrária, o abastecimento alimentar e o cuidado com o ambiente, entre outros. Nesse sentido, a preocupação com a pobreza rural se tornou uma preocupação tanto para o desempregado urbano das metrópoles, quanto para a classe média, impressionada com o aumento da violência nas cidades, e mesmo para os semterra do campo. Talvez seja por essas razões que o combate à pobreza e à miséria rural esteja sensibilizando várias categorias sociais e, com isso, fazendo com que a luta contra o êxodo rural faça parte de diversas políticas governamentais.

\section{4 ÊXODO RURAL}

Mesmo sem que seja algo externado por todos, a busca por melhorias na qualidade de vida, organização econômica e preservação ambiental estão entre os objetivos sociais almejados por muitos. Como exposto no item anterior, nem sempre a qualidade de vida é algo que possa ser almejado por aqueles que vivem nas áreas rurais, afinal, vive-se em uma organização social em que há uma hipervalorização de tudo que é urbano em detrimento ao rural. A consecução deste objetivo é então objetivo de luta por mudanças sociais, de um compromisso com o futuro e a solidariedade entre gerações, como afirmam Schneider e Fialho (2000).

Os autores ainda afirmam que o turismo rural não tem como característica principal a geração de empregos, mas que é capaz de alterar as relações, proporcionando às famílias empreendedoras um bem-estar perceptível, vinculado a melhores condições financeiras e a uma maior inserção social.

Corroborando essa percepção, Elesbão (2000), Almeida e Souza (2004) citados por Schneider e Fialho (2000) mostram no resultado de suas pesquisas em Lages-SC e 
São Martinho-SC, a unanimidade entre as pessoas que estavam trabalhando diretamente em atividades turísticas nestes municípios: o turismo rural melhorou consideravelmente o padrão de vida da população, gerou alguns empregos e ocupações e proporcionou benefícios concretos para a comunidade como um todo. Evita-se, desta forma, o êxodo em massa em direção aos centros urbanos, mantendo uma perspectiva real de qualidade de vida.

\subsection{TURISMO E ATIVIDADE HOTELEIRA}

Em 2008 foi editada pelo governo federal a Lei 11.771 (BRASIL, 2008), definindo o que seria considerado meio de hospedagem, como aquelas instalações que prestassem serviços de alojamento temporário e de uso individual e exclusivo, mediante contrato tácito ou expresso, e com pagamento de diárias.

O desenvolvimento do turismo e da atividade hoteleira foi marcado por vários movimentos históricos. A hotelaria, no decorrer dos anos, passou por mudanças significativas onde diversos serviços foram a ela agregados até que se chegasse a sua concepção atual, em que inovações e facilidades na atividade foram trazidas por processos tecnológicos e aperfeiçoamentos nos produtos e serviços oferecidos. Nestes foram introduzidos padrões de qualidade cada vez mais específicos e mutáveis, tendo como peça fundamental o fator humano (CASTELLI, 2003).

Neste sentido, Teixeira e Souza (2012) afirmam que o turismo vem incorporando as transformações que gradualmente e constantemente acompanham a história da sociedade mundial. São diversos os aspectos que permeiam essas mudanças, e que vão do ambiental ao econômico, mas a eles transcendendo.

Já as atividades desenvolvidas em espaços não urbanos, associadas ao turismo e ao modo de vida das famílias rurais acabou se demonstrando como uma estratégia promissora para o desenvolvimento local, afirmou Blanco (2006). E ainda há outros ganhos com a atividade turística neste meio. Pode-se citar a preocupação com a sustentabilidade, seja do ambiente ou da própria atividade rural em si mesma (GUZZATTI; SAMPAIO; CORIOLANO; 2013).

Outros aspectos, diversos ao incremento da renda familiar, também surgem quando vão: 
[...] sendo criados múltiplos eventos com circuitos e rotas turísticas adequadas às tradições culturais e às condições naturais das regiões. Várias modalidades do turismo, como o turismo alternativo, turismo ecológico, agroturismo, entre outros, estão atraindo os moradores da cidade rumo ao campo. Com efeito, o turismo no espaço rural engloba todas essas formas de turismo e se associa aos agricultores familiares de maneira inovadora, valorizando e preservando o patrimônio rural. [...] Ao apresentar os modos tradicionais e artesanais da agricultura familiar como produto turístico, o turismo rural amplia suas possibilidades, consolidando o modo de vida rural como um atrativo aos moradores das metrópoles. $O$ estilo de vida, os costumes e o modo de produção das famílias rurais, ou seja, a cultura do campo, passa despertar o interesse não só dos grandes centros urbanos, mas também dos municípios vizinhos. Compartilhar tradições gastronômicas e culturais que poderiam cair no esquecimento são resgatadas e valorizadas. Pode-se comprovar que nessas regiões, o turismo tradicional de massa está dando lugar a essa nova forma de turismo mais pessoal e acolhedor. O turista convive e se relaciona diretamente com as rotinas diárias das famílias rurais, aprendendo na prática, suas tradições, hábitos e costumes. Conseqüentemente, há o resgate da autoestima do homem do campo, pois a valorização da identidade cultural rural é incentivada pela presença dos turistas urbanos, estimulando a produção e o desenvolvimento local. (BLANCO, 2006, p. 44)

\section{Corroborando essa visão, pode-se observar claramente que:}

[...]A chegada do turismo às áreas rurais surge como alternativa socioeconômica para os agricultores e uma opção de lazer para aqueles que procuram atividades turísticas diferenciadas. Por conseguinte, visto que o turismo é uma atividade que origina uma série de dinâmicas nos locais que o incorporam, proporcionando perspectivas para a melhoria da qualidade de vida de populações rurais, este pode estar atuando como promotor do desenvolvimento de comunidades rurais. [...] Os espaços rurais, na atualidade, abordam crescentemente os temas vinculados às "novas ruralidades", pautando-se, assim, em questionamentos sobre o que é o rural, qual sua dimensão espacial, social, cultural, econômica e ambiental. Essas reflexões sobre a ruralidade emergente insurgem conjuntamente a um panorama de mudanças em que a adesão às atividades não agrícolas como meio de ocupação da população rural ganha cada vez mais destaque. Dentre elas, a crescente implantação de atividades turísticas em espaços rurais como meio de desenvolver e revitalizar comunidades rurais, nas mais diferentes esferas, faz com que o turismo desponte entre as atividades não agrícolas rurais a que ganha maior notoriedade. (TEIXEIRA e SOUZA; 2012; p.232)

Assim, é razoável aceitar que, quando se está falando de turismo rural se está referindo ao conjunto de modalidades e empreendimentos que têm lugar no espaço rural, de organização econômica e produtiva que prestam serviços e/ou atividades de acolhimento, transporte, hospedagem, alimentação, lazer, recreação e entretenimento e outros que se estará referindo ao mencionar o turismo praticado em áreas rurais. $\mathrm{O}$ próprio espaço rural é a referência. Entende-se como rural toda área ou espaço físico 
que estiver localizado fora do perímetro urbano, cuja definição é dada a partir da respectiva legislação municipal onde estiver situada.

\section{METODOLOGIA}

O presente trabalho está caracterizado como Pesquisa de Campo, uma vez que a pesquisa de campo

[...] é aquela utilizada com o objetivo de conseguir informações e/ou conhecimentos acerca de um problema para o qual procuramos uma resposta, ou de uma hipótese, que queiramos comprovar, ou, ainda, descobrir novos fenômenos ou as relações entre eles. Consiste na observação de fatos e fenômenos tal como ocorrem espontaneamente, na coleta de dados a eles referentes e no registro de variáveis que presumimos relevantes, para analisálos. (PRODANOV; FREITAS, 2013, p. 59).

Segundo os autores, as fases da pesquisa de campo requerem, em primeiro lugar, a realização de uma pesquisa bibliográfica sobre o tema em questão. Ela servirá, como primeiro passo, para saber em que estado se encontra atualmente o problema, que trabalhos já foram realizados a respeito e quais são as opiniões reinantes sobre o assunto. Como segundo passo, permitirá que se estabeleça um modelo teórico inicial de referência, da mesma forma que auxiliará na determinação das variáveis e na elaboração do plano geral da pesquisa. Em segundo lugar, de acordo com a natureza da pesquisa, serão determinadas as técnicas a ser empregadas na coleta de dados e na definição da amostra, que deverá ser representativa e suficiente para apoiar as conclusões.

A presente pesquisa foi delineada, ainda, como qualitativa, uma vez que não houve a coleta de valores, mas sim de percepções quanto a fatos e possibilidades deles decorrentes, sem preocupações quantitativas quanto aos mesmos, pois, segundo Lakatos e Marconi (2010), aspectos comportamentais têm uma melhor compreensão quando estudados à luz qualitativa.

Quanto à lógica, a presente pesquisa se enquadra como indutiva, conforme Prodanov e Freitas (2013). Segundo afirmam os autores, este método é responsável pela generalização, partindo de alguns dados em particular para chegar a questões mais amplas. Segundo os autores, ainda, parte-se de um: 
[...] fenômeno para chegar a uma lei geral por meio da observação e de experimentação, visando a investigar a relação existente entre dois fenômenos para se generalizar. No raciocínio indutivo, a generalização deriva de observações de casos da realidade concreta. Nesse método, partimos da observação de fatos ou fenômenos cujas causas desejamos conhecer. A seguir, procuramos compará-los com a finalidade de descobrir as relações existentes entre eles. Por fim, procedemos à generalização, com base na relação verificada entre os fatos ou fenômenos. (PRODANOV; FREITAS, 2003, p. 28-29).

O método utilizado foi o Método Observacional. Prodanov e Freitas (2013) apontam que o método observacional é um dos mais utilizados nas ciências sociais e apresenta alguns aspectos interessantes. "Por um lado, pode ser considerado como o mais impreciso. Mas, por outro lado, pode ser tido como um dos mais modernos, por possibilitar o mais elevado grau de precisão nas ciências sociais." (GIL, 2008). Ainda, mencionando Gil (2008) os autores mencionam que o método observacional difere do experimental em apenas alguns aspectos na relação entre eles: "nos experimentos, o cientista toma providências para que alguma coisa ocorra, a fim de observar o que se segue, ao passo que, no estudo por observação, apenas observa algo que acontece ou já aconteceu." (GIL, 2008 apud PRODANOV; FREITAS, 2013).

\subsection{POPULAÇÃO E AMOSTRA}

A população estava composta por aproximadamente 2790 pessoas (IBGE, 2010), residentes na zona rural de Lages, totalizando $2 \%$ da população total do município. Já a amostra foi composta por três produtores rurais, da região de Lages (SC), escolhidos por conveniência, uma vez que eram conhecidos do pesquisador, e encontravam-se a não mais que $10 \mathrm{Km}$ umas das outras, sendo possível inferir aspectos territoriais não muito distintos entre si.

\subsection{INSTRUMENTO DE COLETA}

A presente pesquisa foi efetivada com a aplicação de um questionário de entrevista contendo perguntas abertas, de fácil entendimento por parte dos entrevistados, haja vista a baixa escolarização ainda preponderante no ambiente rural, mas que propiciou um entendimento com maior profundidade daquilo que se pretendia estudar. 
A entrevista foi feita de forma não estruturada uma vez que, dado o caráter subjetivo da pesquisa, as respostas foram coletadas de acordo com a percepção pessoal do próprio entrevistado.

\subsection{PROCEDIMENTO DE COLETA}

Foi feita uma viagem à região de interesse, em Lages (SC), com visitas às propriedades escolhidas pelo pesquisador, e que se considerou ter potencial para acolher pessoas em atividades de turismo, em um ambiente mais rústico. Nestas visitas, os proprietários foram entrevistados, seguindo o roteiro constante no Instrumento de Coleta, conforme mostrado no Apêndice deste trabalho, e as suas respostas anotadas adequadamente.

\subsection{ANÁLISE}

Os dados obtidos foram analisados à luz das teorias e práticas utilizadas no universo hoteleiro, quanto à potencialidade de utilização das propriedades como meio de hospedagem e sua viabilidade. Também foi analisado o impacto da possível renda extra para a permanência das famílias entrevistadas à sua atividade rural.

As respostas foram analisadas de forma agrupada, segundo o tema eixo da pergunta, mostradas a seguir, nos resultados.

\section{RESULTADOS}

Tendo como base as entrevistas realizadas com os proprietários, que compuseram a amostra deste trabalho, chegou-se ao retrato apresentado a seguir, segundo os pontos de interesse pesquisados, quanto aos seguintes aspectos:

- Atividade rural: todos os entrevistados mencionaram estar na atividade rural desde muito tempo. As atividades produtivas na "roça", segundo suas próprias palavras, já faziam parte do contexto deles. O tempo variou de 32 a 65 anos na atividade rural. A tradição vinha desde, pelo menos, os avós. Eram no mínimo três gerações executando a mesma atividade. 
- Produção agrícola: os itens eram essencialmente os mesmos, com pequenas variantes. À exceção de um entrevistado, que mencionou produzir em escala maior que os demais, suas produções eram bastante diversificadas, e em baixo volume. A produção de itens alimentícios era o foco principal das propriedades. Pôde-se observar, também, a alternância de produção, motivada por dificuldades de custeio e manutenção, como no caso de pomares de maçãs e pêssegos. E pelo fato de ser pequena a produção, não era raro atender somente à subsistência das famílias. Estavam sendo diversos os fatores que interferiam, como um deles relatou, que apesar de ter feito uma boa colheita de feijão, não conseguiu vender. Assim, ainda tinha que arcar com os custos de armazenagem. Verificou-se haver pouco excedente nos ganhos.

- Desejo de permanência no local atual: percebeu-se que já havia um sentimento de envelhecimento, de cansaço com a "lida muito pesada". A escassez de mão de obra, pois "é muito difícil a matéria humana" e a incerteza dos resultados da produção agrícola estavam sendo fatores que tornavam a saída da atividade rural uma possibilidade real, quase que iminente.

- Autopercepção: A percepção da importância das atividades desenvolvidas encontrava-se em um patamar de baixa autoestima dos proprietários. Não estavam conseguindo ver, em suas atividades rotineiras, atratividade. Segundo os depoimentos, os atrativos eram ligados principalmente ao ambiente natural do entorno, ou a expectativa de comer com fartura. Apenas quando questionados sobre as atividades diárias, após breve reflexão, começavam a descrever atividades que poderiam exercer algum tipo de atração: feitio de bolachas, queijos, sabão, plantio das roças. Ainda assim, a maioria não demonstrou acreditar que alguém pudesse pagar para acompanhar sua rotina, pelo fato de ser extremamente árdua. 
- Instalações para hospedagem: foram unânimes em reconhecer a simplicidade de suas casas, a deficiência das instalações e necessidade de melhorias, como compra de enxoval, reforma ou construção de mais banheiros, melhorias gerais nas casas. Apesar desta falta de preparo em suas propriedades, todos estariam dispostos a receber hóspedes. Mas seria uma decisão que envolveria a todos na propriedade, e "não poderia interferir na rotina". Assim como a decisão de hospedar seria conjunta, os benefícios da renda extra também o seriam. Todos seriam beneficiados, uma vez que seria um "alívio" nas contas, que estavam sempre no limiar da inadimplência. Ou então, "a mulher ia me pedir menos dinheiro".

- Relação com os vizinhos: este ponto acabou revelando o quão conflituosas estavam sendo as relações entre a vizinhança. Problemas de invasão de terras, furtos, não pagamento de dívidas, ou mesmo abigeato, estavam sendo agravantes que dificultavam o entendimento entre os vizinhos mais próximos. Houve unanimidade em afirmar ser quase impossível uma relação mais próxima entre os mesmos. Desta maneira, as condições de partilhar atividades, equipamentos, produtos ou serviços, na hipótese de recepção de hóspedes, tornava-se bastante restrita.

- Disponibilidade em receber turistas: mesmo com a dificuldade de trabalho coletivo ou comunitário, todos se mostraram abertos a recepcionar visitantes, ensinando-os e orientando-os sobre suas atividades e afazeres. Verificou-se haver até uma certa preocupação se saberiam receber bem ou não, pois "quando você vive entocado no sítio, vai ficando jeca". Contudo, a preocupação em não ter a rotina atrapalhada foi um ponto comum entre todos, também. Com isto em mente, quase todos afirmaram ter disponibilidade de algum recurso para investir em melhorias para investimentos no sentido da hospitalidade. 
- Atividade Turística: pôde-se inferir haver uma forte influência da rotina cansativa, pois todos foram unânimes ao afirmar que fazer turismo era, basicamente, descansar. Sair de seu ambiente para poder descansar. Houve o relato recorrente das dificuldades em sair da propriedade para fazer alguma espécie de turismo. Além das dificuldades da própria atividade, ainda haveria a deficiência de mão de obra confiável. Foi relatado inclusive a morte de gado por falta de cuidados da pessoa que havia ficado responsável. Neste cenário, as saídas eram esparsas e breves. Apenas um proprietário relatou que costumava ir ao litoral com a família, passar alguns dias na praia, umas duas vezes por ano. E em geral, em casas de parentes.

\subsection{ANÁLISE DO POTENCIAL DE HOSPEDAGEM NOS LOCAIS}

A partir dos dados levantados através das entrevistas, o quadro a seguir apresenta quanto à possibilidade de oferta de hospedagem / acolhimento nas propriedades, os pontos considerados fortes no momento em que foram feitas as entrevistas, bem como daqueles que seriam limitantes ao mesmo objetivo:

QUADRO1: PONTOS FORTES E PONTOS FRACOS.

\begin{tabular}{|c|c|}
\hline PONTOS FORTES & PONTOS LIMITANTES \\
\hline $\begin{array}{l}\text { O resultado das entrevistas deixou claro haver uma } \\
\text { abertura para a possibilidade de inclusão de } \\
\text { hospedagem, por parte dos proprietários, nos locais } \\
\text { visitados. }\end{array}$ & $\begin{array}{l}\text { Rotina estafante. A inclusão da atividade } \\
\text { hospitaleira, nas condições de serviço e } \\
\text { disponibilidade de mão de obra poderia ser } \\
\text { considerada como mais uma atividade a } \\
\text { sobrecarregar a já carregada rotina. }\end{array}$ \\
\hline $\begin{array}{l}\text { Existência de possibilidade de investimento, } \\
\text { mesmo que pequeno, em melhorias na estrutura, } \\
\text { adequando-as à prática de hospedagem, mantendo- } \\
\text { se a rusticidade. }\end{array}$ & $\begin{array}{l}\text { Preocupação em não ser atrapalhado no seu dia a } \\
\text { dia. Alguém acompanhando, perguntando, } \\
\text { experimentando poderia ser visto como um entrave } \\
\text { ao bom andamento das atividades. }\end{array}$ \\
\hline $\begin{array}{l}\text { Ainda que discreto, houve reconhecimento de que } \\
\text { poderia haver algo que interessasse outras pessoas } \\
\text { a visitá-los, conhecer seu estilo de vida. }\end{array}$ & $\begin{array}{l}\text { Necessidade de investimentos. A escassez de } \\
\text { recursos foi recorrente, e poderia ser um } \\
\text { impeditivo. A adequação dos locais certamente } \\
\text { exige mais recursos do que os disponíveis. }\end{array}$ \\
\hline Afastamento do centro urbano. & $\begin{array}{l}\text { Acesso aos locais via estradas de terra, com muitas } \\
\text { pedras soltas e pó, e lama em dias de chuva, com } \\
\text { extensão entre } 5 \text { a } 10 \mathrm{Km} \text {. }\end{array}$ \\
\hline Ambiente natural privilegiado. & $\begin{array}{l}\text { A relação conflituosa entre vizinhos poderia se } \\
\text { tornar um impeditivo a ser fortemente considerado. }\end{array}$ \\
\hline
\end{tabular}

FONTE: Elaborado pelos autores (2019).

Verifica-se, pelo quadro acima mostrado, que houve certa abertura quanto à possibilidade de receber turistas em suas propriedades, por parte dos proprietários. 
Contudo, essa mesma vontade acaba por ser mitigada pela constante falta de recursos para investimentos, ou mesmo sendo atropelada pela rotina dura e estafante. Foi possível observar também uma grande dificuldade em visualizar atratividade em seus afazeres, talvez motivada pelas características de suas próprias atividades, ou mesmo por estarem acostumados a ela.

Outro ponto levantado mostrou-se em forma de desalento quanto à atuação do poder público, com estradas e acessos mal conservados, precários. Ou então na relação interpessoal, cuja mediação se mostrou necessária para a melhoria das condições de trabalho e vida dos referidos proprietários rurais.

\section{CONCLUSÕES}

As entrevistas com os proprietários revelaram pessoas receptivas e dispostas a conversar sobre abrir suas propriedades a estranhos. O ambiente natural, as paisagens, o afastamento ou isolamento dos centros urbanos podem, de fato, serem grandes atrativos. Contudo, as condições não estavam favoráveis, pelo menos nestas propriedades, no momento da pesquisa. A necessidade de investimentos maiores do que aqueles que estavam disponíveis, inviabilizaria a abertura de espaço para a hospedagem, em curto prazo.

Concluiu-se, também, a impossibilidade da prática de turismo e hospedagem comunitária, uma vez que a incapacidade de colaborar pacificamente com os moradores do seu entorno inviabilizaria a atividade cooperativa, colaborativa por natureza. Enquanto os conflitos existentes não forem resolvidos, ou minimamente mediados, o isolamento de cada um em sua propriedade continuaria a ser a realidade encontrada.

Assim, sugere-se para futuras pesquisas, que se investiguem as causas da tensão existente entre os proprietários agricultores. Além das dificuldades inerentes à atividade em si, relações tensas e conflituosas entre vizinhos, em especial na zona rural, onde as distâncias maiores e o acesso a recursos são mais restritos, a relação não amigável poderia ser um fator decisivo para o abandono das atividades. Além de investigar as causas, sugere-se também que se façam estudos de como mediar e minimizar os conflitos existentes. 
Como sugestão, com o intuito de driblar a escassez de recursos de maior monta, que poderia ser um fator limitante importante, quando se trata de investimento em infraestrutura, sugere-se que, caso os proprietários assim o desejarem, sejam iniciadas reformas e ampliações paulatinamente, conforme a disponibilização de recursos. Assim, em médio prazo, as propriedades poderiam estar minimamente adequadas a receber hóspedes com conforto e qualidade.

Por outro lado, como a pesquisa se restringiu a uma amostra pequena de agricultores na região, talvez não represente a real condição dos demais agricultores da localidade. Percebeu-se, ainda como limitação, a tendência dos entrevistados, principalmente quando se referia a conceituação de turismo, hospitalidade, que as respostas eram dadas na expectativa que fossem o que o pesquisador queria ouvir, e não o que pensavam de fato.

\section{REFERÊNCIAS}

ABRAMOVAY, R. O capital social dos territórios: repensando o desenvolvimento rural. Economia aplicada, v. 4, n. 2, p. 379-397, 2000.

BLANCO, E. S. O turismo rural em áreas de agricultura familiar: as "novas ruralidades" e a sustentabilidade do desenvolvimento local. Caderno Virtual de Turismo, v. 4, n. 3, p.44-49, 2006.

BOTELHO FILHO, F. Agricultura Familiar e Desenvolvimento Territorial, contribuições ao debate. Brasília: Universidade de Brasília, Centro de Estudos Avançados Multidisciplinares, Núcleo de Estudos Avançados, v. 5, n. 17, 2005.

BRASIL. Lei ${ }^{0} 11.771$, de 17 de setembro de 2008. Dispõe sobre a Política Nacional de Turismo, define as atribuições do Governo Federal no planejamento, desenvolvimento e estímulo ao setor turístico; revoga a Lei no 6.505, de 13 de dezembro de 1977, o Decreto-Lei no 2.294, de 21 de novembro de 1986, e dispositivos da Lei no 8.181, de 28 de março de 1991; e dá outras providências. Portal da Legislação, Brasília, 17 set. 2008. Disponível em:

$<$ http://www.planalto.gov.br/ccivil_03/_ato2007-2010/2008/lei/111771.htm>. Acesso em: 10 mai. 2018.

CASTElli, G. Administração Hoteleira. Caxias do Sul: EDUCS, 2003.

ELESBÃO, I. O espaço rural brasileiro em transformação. Finisterra, v. 42, n. 84, p.47-65, 2007.

GIL, A. C. Metodologia da pesquisa social. São Paulo: Atlas, 2008. 
GUZZATTI, T. C; SAMPAIO, C. A. C; CORIOLANO, L. N. M. T. Turismo de base comunitária em territórios rurais: caso da Associação de Agroturismo Acolhida na Colônia (SC). Revista Brasileira de Ecoturismo, v. 6, n. 1, p. 93-106, 2013.

HANAI, F. Y.; SILVA NETTO, J. P. O turismo como alternativa de desenvolvimento sustentável do espaço rural: discussões e proposições no Brasil. In: CONGRESO LATINOAMERICANO DE SOCIOLOGÍA RURAL. Anais... Quito, 2006. p. 1-15.

IBGE (INSTITUTO BRASILEIRO DE GEOGRAFIA E ESTATÍSTICA). Censo demográfico 2010. Disponível em:

$<$ https://censo2010.ibge.gov.br/sinopse/index.php?dados=29\&uf=42>. Acesso em: 10 out. 2018.

LAKATOS, E. M; MARCONI, M. A. Fundamentos de metodologia científica. 7 ed. São Paulo: Atlas, 2010.

LINDNER, M; FERREIRA, E. R; SOUZA, M. A exploração das ruralidades na revalorização do espaço rural: estímulos ao desenvolvimento do turismo na Quarta Colônia de Imigração Italiana, RS-Brasil. ENCUENTRO DE GEÓGRAFOS DE AMÉRICA LATINA, Anais... Montevideo, 2009. Disponível em $<$ http://www.lume.ufrgs.br/bitstream/handle/10183/17120/000690494.pdf?sequence=1> Acesso em: 25 abr. 2018.

NASCIMENTO, C. A. Pluriatividade, pobreza rural e políticas públicas. Campinas: [s.n.], 2005.

PRODANOV, C. C; FREITAS, E. C. Metodologia do trabalho científico: métodos e técnicas da pesquisa e do trabalho acadêmico. Novo Hamburgo: Feevale, 2013.

SANTOS, N. P; CUNHA, L. S. Novas oportunidades para o espaço rural: análise exploratória no Centro de Portugal (2007). In: VI CONGRESSO DA GEOGRAFIA PORTUGUESA, Anais... Lisboa, 2007. p. 1-18.

SCHNEIDER, S; FIALHO, M. A. V. Pobreza rural, desequilíbrios regionais e desenvolvimento agrário no Rio Grande do Sul. Teoria e Evidência Econômica, v. 8, n. 15 , p. $117-149,2000$.

SCHNEIDER, S. Turismo em Comunidades Rurais: inclusão social por meio de atividades não-agrícolas. In: Ministério do Turismo (Org.). Turismo Social. Rio de Janeiro: IBAM, 2006.

TEIXEIRA, A. R; SOUZA, M. A Valorização da Ruralidade a partir do Turismo: Roteiro Turístico Caminhos Rurais, Porto Alegre, Rio Grande do Sul, Brasil. Turismo e Sociedade, v. 5, n. 1, p. 231-251, 2012.

YIN, R. K. Estudo de caso: planejamento e métodos. 2 ed. Porto Alegre: Bookman, 2001. 


\section{APÊNDICE}

Questionário aplicado nas entrevistas

1. Há quanto tempo é produtor rural? É de família?

2. O que produz?

3. A produção é suficiente para sua subsistência e da sua família?

4. Em algum momento, já deixou o campo para morar na cidade? Se sim, quais motivos? Se não, haveria algum motivo que o levaria a abandonar o campo?

5. Você acha que a sua propriedade tem algo que pudesse atrair as pessoas "da cidade"? Você acha que suas instalações teriam condições de receber alguém? (como banheiros, quartos, enxoval, refeições, etc.)

6. Dentre as suas atividades, você acredita que alguém se interessaria em ver como é feito?

7. Você acha que alguém pagaria para passar um tempo aqui, vivendo a sua rotina, desfrutando do seu estilo de vida?

8. Você e sua família estariam dispostos a receber alguém como hóspede, recebendo um pagamento para isso?

9. Caso isto viesse a acontecer, como este rendimento extra lhe afetaria?

10. A sua relação com os vizinhos próximos é boa?

11. Você acha que haveria interesse deles em realizar alguma atividade em grupo? Vocês partilham / partilhariam alguns serviços, instalações ou produtos?

12. Você estaria disposto a dedicar parte de seu tempo em receber, hospedar e/ou orientar atividades com possíveis visitantes?

13. Caso haja interesse em desenvolver alguma atividade relacionada à hospitalidade, haveria alguma disponibilidade de investimento?

14. O que você acha da atividade "Turismo"?

15. Você e sua família costumam fazer alguma espécie de turismo? Qual? Com que frequência?

Recebido em: 18-12-2018.

Aprovado em: 13-11-2019.

Versão aprovada para publicação em: 14-11-2019. 